ECOLOGICA, Vol. 28, No 104 (2021), 619-624

https://doi.org/10.18485/ecologica.2021.28.104.18

Originalni naučni rad

UDC: $635.21 / .24: 631.4(497.113)$

\title{
Uticaj nastiranja zemljišta na morfološke osobine mladog krompira
}

\section{The influence of mulching on morphological traits of early potato}

\author{
Vuk Vujasinović ${ }^{,}$Zorana Srećkov ${ }^{2 *}$, Zorica Mrkonjić ${ }^{3}$, Mirjana Bojović ${ }^{4}$, \\ Anđelko Miškovićs, Olivera llić 6 , Gordana Racić \\ ${ }^{1}$ Generali osiguranje Srbija, Vladimira Popovića 8, 11070 Beograd, Srbija / \\ Generali insurance Serbia, Vladimira Popovića 8, 11070 Belgrade, Serbia \\ 2,3,4,7Univerzitet Educons, Fakultet ekološke poljoprivrede, Vojvode Putnika 87, Sremska Kamenica, Srbija / \\ Faculty of Ecological Agriculture, Educons University, Vojvode Putnika 87, Sremska Kamenica, Serbia \\ ${ }^{5}$ Poljoprivredni fakultet, Univerzitet u Novom Sadu, trg Dositeja Obradovića 8, 21102 Novi Sad, Srbija / Faculty \\ of Agriculture, University of Novi Sad, Dositeja Obradovića Square 8, 21102 Novi Sad, Serbia \\ ${ }^{6}$ Pheno Geno Roses D.O.O., Trg Maršala Tita 75, 23326 Ostojićevo, Srbija / \\ Pheno Geno Roses D.O.O., Maršala Tita Square 75, 23326 Ostojićevo, Serbia \\ ${ }^{*}$ Autor za prepisku / Corresponding author
}

Rad primljen / Received: 07.09.2021, Rad prihvaćen / Accepted: 03.11.2021.

Sažetak: Ovo istraživanje sprovedeno je sa ciljem da se ispita uticaj nastiranja na komponente prinosa i prinos krtole mladog krompira. Ogled je postavljen u tri vegetacione sezone na jednom lokalitetu (Begeč), po split-plot sistemu u pet ponavljanja. Uticaj malčovanja ispitivan je na sortama krompira Cleopatra i Riviera. Sadnja je obavljena mašinski, jedna krtola po kućici, na međuredni razmak od $65 \mathrm{~cm}$, a razmak u redu $30 \mathrm{~cm}$. Analizirane su broj krtola po biljci, masa krtola po biljci (g) i prinos mladog krompira (kg/ha). Analiza varijanse je urađena po split-plot modelu na osnovu prosečnih srednjih vrednosti. Poređenje srednjih vrednosti urađeno je primenom LSD testa. Visoko značajan efekat tretmana (nastiranja) utvrđen je za sve tri proučavane osobine. Obe proučavane sorte ostvarile su statistički značajno veći prinos i masu krtola po biljci pri primeni nastiranja, dok je osobina broj krtola po biljci bila veća na kontrolnoj varijanti, ali razlika između kontrole i tretmana nije bila statistički značajna. Statistički značajno više vrednosti za sve tri proučavane osobine ustanovljene su kod sorte Riviera. Na osnovu dobijenih rezultata može se zaključiti da primena nastiranja ima pozitivan uticaj na prinos mladog krompira, što pruža mogućnost za širu primenu ove specifične agrotehničke mere u proizvodnji mladog krompira.

Ključne reči: krompir, nastiranje, prinos, komponente prinosa.

\begin{abstract}
The effect of mulching on early potato yeald was investigated on two potato varieties, Cleopatra and Riviera. The experiment was set up in three vegetation seasons at one locality (Begeč), according to the split-plot design with five replications. Tuber number per plant, tuber weight per plant $(\mathrm{g})$ and the yield $(\mathrm{kg} / \mathrm{ha})$ were analyzed. Analysis of variance was performed according to the split-plot design based on average means. The comparison of mean values was done using the LSD test. A highly significant effect of treatment was determined for all three studied traits. Both studied cultivars achieved a significantly higher yield and tuber mass per plant when mulch was applied, while the trait tuber number per plant was higher in the control variant (bare soil). Statistically significantly higher values for all three studied traits were found in the Riviera variety. According to results, it can be concluded that the application of mulch has a positive impact on the yield of early potato, which provides an opportunity for wider application of this specific agricutural measure in the production of early potatoes.
\end{abstract}

Keywords: potato, mulching, yield, components of yield.

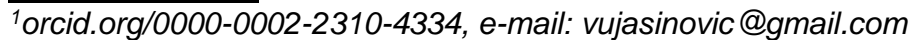

2orcid.org/0000-0002-2278-1077, e-mail: sreckovzorana@yahoo.com

3orcid.org/0000-0001-5934-8974, e-mail: zoricamrkonjic@gmail.com

4orcid.org/0000-0002-5767-8221, e-mail:mimatopic@gmail.com

5orcid.org/0000-0001-6710-040X, e-mail:miskovic.andjelko@gmail.com

6orcid.org/0000-0003-1668-1456,e-mail: o.ilic@phenogenoroses.com

7orcid.org/0000-0003-1404-4015, e-mail:gordana.racic84@gmail.com
} 


\section{UVOD / INTRODUCTION}

Naučno-tehnološki razvoj doveo je do velikog broja pozitivnih promena za čovečanstvo. Međutim, pored svih pozitivnih promena svedoci smo i mnogih opasnosti koje se najviše manifestuju u zagađenju životne sredine kroz zagađenje vode, vazduha i zemljišta (Dinić i dr., 2021). Kao jedan od najvećih zagađivača životne sredine navodi se savremena poljoprivredna proizvodnja (Stefanović i dr., 2009) koja se karakteriše sve većom upotrebom mineralnih đubriva i hemijskih sredstava za zaštitu biljaka što sve ima negativan uticaj pre svega na zemljište (Radić i dr., 2020), a indirektno i na ljudsko zdravlje (Amidžić, Biočanin, 2005). Sa druge strane, usled klimatskih promena, globalne i lokalne atmosferske prilike se sve više menjaju (poplave, oluje sa gradom, suša, ekstremne temperature) što se negativno odražava na poljoprivrednu proizvodnju i prehrambenu sigurnost (Stefanović, Obradović, 2010). Sve ovo nameće primenu metoda u poljoprivredi koje će ublažiti negativan uticaj klimatskih promena.

Jedna od agrotehničkih mera koja sa jedne strane može da smanji upotrebu štetnih inputa u poljoprivredi, a sa druge strane da pozitivno utiče na plodnost zemljišta, a time i na stabilniju poljoprivrednu proizvodnju je primena nastiranja ili malčovanja. Nastiranje zemljišta ne samo da ima pozitivne efekte na životnu sredinu kroz održavanje i povećanje sadržaja hranljivih elemenata u zemljištu, čuvanje strukture zemljišta, povećanje mikrobiološke aktivnosti, sprečavanje erozije zemljišta (Iqbal et al, 2020), nego je i značajno prilikom proizvodnje zdravstveno bezbedne hrane jer smanjuje razvoj korova, razvoj bolesti i napade štetočina čime direktno utiče na smanjenu upotrebu pesticida.

Krompir predstavlja jednu od osnovnih gajenih kultura, kako zbog površina na kojima se gaji (među prvih deset kultura po površinama na kojima se gaji; FAO, 2019), tako i po značaju u ljudskoj ishrani. Krompir je svakodnevna komponenta u ljudskoj ishrani i važna sirovina u prerađivačkoj industriji (Marković i dr., 2006). U ishrani se koristi zreo, kada je pokožica očvrsla, odebljala i potpuno srasla sa unutrašnjim delom krtole, ili kao mladi (rani) krompir, odnosno još potpuno neformirane krtole. Mladi krompir je jako cenjen u ishrani i zbog svog izuzetnog kvaliteta predstavlja visoko nutritivno vrednu namirnicu u prolećnom periodu, kada je izbor ostalih povrtarskih kultura relativno mali.

Pored toga što povećava zdravstvenu bezbednost hrane, istraživanja velikog broja naučnika pokazala su da primena različitih materijala za nastiranje pozitivno utiče i na prinos i kvalitet poljoprivrednih kultura (Bhatta et al, 2020; Yagi et al, 2020; Oljača et al, 2018; Oljača, 2016). Iz tog razloga cilj ovog rada je bio da se ustanovi uticaj nastiranja (malčovanja) na prinos krtole mladog krompira, kao najvažnije agronomske osobine kod dve rane sorte krompira, kao i uticaj malčovanja na neke od najvažnijih komponenti prinosa, broj i masu krtola po biljci.

\section{MATERIJAL I METODE / MATERIAL AND METHODS}

Kako bi se ispitao uticaj nastiranja na komponente prinosa i prinos mladog krompira, postavljen je poljski ogled u tri vegetacione sezone, na lokalitetu Begeč (selo u opštini Novi Sad, $45^{\circ} 14^{\prime} 35^{\prime \prime} \mathrm{N}$; $19^{\circ} 36^{\prime} 31^{\prime \prime}$ ). Ogled je postavljen po split-plot sistemu u pet ponavljanja.

Uticaj malčovanja ispitivan je na sortama krompira Cleopatra (faktor $\mathrm{a}_{1}$ ) i Riviera (faktor $\mathrm{a}_{2}$ ). Sorta Cleopatra (HZPC - Holandija) je jedna od najpoznatijih ranih sorti, dužine vegetacije od 85 do 90 dana. Biljke ove sorte su srednje visine, srednje razgranate, brzog porasta. Formiraju 8-9 veoma krupih krtola. Krtole su ovalnog oblika, svetložute boje mesa i crvene pokožice. Riviera (Agrico - Holandija) je rana sorta (80-85 dana); ima dobar početni rast cime, koji dobro pokriva zemljište. Formira 8-9 ovalnookruglih, krupnih krtola žute boje pokožice i svetlo žute boje mesa (llin i dr., 2015).

$\mathrm{U}$ okviru faktora $\mathrm{b}$ ogled je obuhvatio dve varijante: kontrolnu varijantu - klasičan način proizvodnje $\left(b_{1}\right)$ i primenu malč folije $\left(b_{2}\right)$. Malčovanje je urađeno istovremeno sa sadnjom, zatamnjenom folijom debljine $0.012 \mathrm{~mm}$ i širine $120 \mathrm{~cm}$.

Sadnja je obavljena mašinski, jedna krtola po kućici, uz formiranje bankova, na međuredni razmak od $65 \mathrm{~cm}$, a razmak u redu $30 \mathrm{~cm}$. Za sadnju je korišten kvalitetan sadni materijal klase A, a krtole su pre sadnje naklijavane po ustaljenoj metodici koju navode Broćić i Barčik (2003).

Analizirane su sledeće osobine: broj krtola po biljci, masa krtola po biljci (g) i prinos mladog krompira $(\mathrm{kg} / \mathrm{ha})$. Kako bi se pratile osobine broj krtola po biljci i masa krtola po biljci uzimani su uzorci na svakih 5 dana (ukupno 10 puta). Prvi uzorak uzet je 40-og dana od sadnje, a poslednji 85-og dana. Uzorci su uzimani od po pet kućica svakog ponavljanja. Prinos mladog krompira utvrđen je prilikom uzimanja poslednjeg uzorka.

U statističkoj obradi podataka korišten je statistički softver GenStat Release 9.1 (Rothamsted Experimental Station). Analiza varijanse je urađena po split-plot modelu na osnovu prosečnih srednjih vrednosti. Poređenje srednjih vrednosti urađeno je primenom LSD testa. 


\section{REZULTATI I DISKUSIJA / RESULTS AND DISCUSSION}

Rezultati dobijeni u ovom istraživanju pokazali su da je primenjena agrotehnička mera visoko značajno uticala na proučavane morfološke osobine mladog krompira, broj krtola po biljci, masu krtola po biljci i prinos krtole mladog krompira.

Broj krtola po biljci jedna je od osnovnih komponenti prinosa mladog krompira. Rezultati analize varijanse pokazali su da je najveći uticaj na varijabilnost ove osobine imala ispitivana sorta $(33,33 \%)$, dok je tretman uticao sa 20,99\% (Tabela 1). Efekat interakcije sorte i primenjene agrotehničke mere iznosio je $17,09 \%$ u ukupnoj varijabilnosti proučavane osobine i bio je statistički značajan. Da sorta utiče na varijabilnost broja krtola po biljci ustanovili su u svom istraživanju i Tessema et al (2020). Ovi autori su proučavali morfološke osobine biljke i krtole (broj listova po biljci, visinu biljke, broj izdanaka, broj krtola po biljci, masu krtola po biljci, ukupan prinos krtole, tržišni prinos krtole, ranostasnost, cvetanje, sadržaj suve materije i sadržaj skroba u krtolama) kod 21 različite sorte krompira i ustanovili su visoko značajan uticaj sorte na varijabilnost svih ispitivanih osobina. Keleta et al. (2018) koji su proučavali uticaj različitih gustina sadnje kod tri varijateta krompira takođe su ustanovili značajan uticaj sorte na varijabilnost broja krtole po biljci.

Tabela 1. Analiza varijanse za broj krtola po biljci Table 1. ANOVA for tuber number per plant

\begin{tabular}{|l|c|c|c|}
\hline \multirow{2}{*}{ Izvor varijacije } & \multirow{2}{*}{ df } & \multicolumn{2}{|c|}{ Broj krtola po biljci } \\
\cline { 3 - 4 } & & Sredinakvadrata & $\%$ \\
\hline Ponavljanja & 4 & 0,026 & 0,65 \\
\hline Sorta $(\mathrm{A})$ & 1 & $5,339^{*}$ & 33,33 \\
\hline Pogreška po a & 4 & 0,454 & 11,33 \\
\hline Tretman (B) & 1 & $3,362^{*}$ & 20,99 \\
\hline A $\times$ B & 1 & $2,738^{*}$ & 17,09 \\
\hline Pogreška po b & 8 & 0,333 & 16,62 \\
\hline
\end{tabular}

${ }^{*} p \leq 0,05 ;{ }^{*} p \leq 0,01$

Prosečan broj krtola po biljci kod sorte Cleopatra bio je statistički značajno različit od prosečnog broja krtola po biljci kod sorte Riviera. Između kontrole i primenjenog tretmana nije ustanovljena statistička značajnost, dok je trogodišnji prosek za ovu osobinu pri upotrebi nastiranja bio statistički značajno manji u odnosu na kontrolu. Razlika sorti po tretmanima na kontrolnoj varijanti bila je visoko statistički značajna, dok pri primeni tretmana (nastiranja) nije pokazala značajnost (tabela 2). Naši rezultati u saglasnosti su sa rezultatima koje su u svojim istraživanjima dobili Marković i dr. (2006). Pomenuti autori su proučavali različite tipove pokrivanja krompira (malčovanje, agrotekstil, niski tuneli) i njihove kom- binacije na komponente prinosa i prinos krtole kod 11 sorti, i ustanovili su da je najveći broj krtola po biljci ostvaren na kontrolnoj varijanti, bez primenjenog tretmana. Autori ovo objašnjavaju činjenicom da iako je najveći broj krtola po biljci bio pri klasičnoj proizvodnji krompira, pri upotrebi nekog od načina prekrivanja dobijen je veći udeo tržišnih (krupnijih) krtola. Naši rezultati su u suprotnosti sa rezultatima koje su u svom istraživanju dobili Bharati et al (2020). Oni su u svom radu ustanovili da je statistički značajno veći broj krtola ostvaren pri upotrebi tamne malč folije u odnosu na upotrebu različitog biljnog otpada i kontrolu. Bhatta et al (2020) takođe su ispitivali različite vrste materijala za malčovanje na prinos i morfološke osobine biljke i krtole krompira i ustanovili su značajnu razliku u broju krtola u zavisnosti od primenjenog materijala. Tako je broj krtola bio statistički značajno veći na perforiranoj crnoj foliji u odnosu na kontrolu, srebrnu i crnu neperforiranu foliju, dok se broj krtola dobijen primenom bele folije nije statistički značajno razlikovao ni kod jednog drugog primenjenog malč materijala.

Tabela 2. Prosečne srednje vrednosti i vrednosti LSD testa za broj krtola po biljci

Table 2. The overall mean values and $L S D$ values for tuber number per plant

\begin{tabular}{|c|c|c|c|c|}
\hline \multirow{2}{*}{\multicolumn{2}{|c|}{ Sorta $(A)$}} & \multicolumn{2}{|c|}{ Tretman (B) } & \multirow{2}{*}{$\begin{array}{l}\text { Prosek } \\
\text { (A) }\end{array}$} \\
\hline & & $\mathrm{K}$ & $\mathrm{N}$ & \\
\hline \multicolumn{2}{|c|}{ Cleopatra } & 8,32 & 8,04 & 8,18 \\
\hline \multicolumn{2}{|c|}{ Riviera } & 9,57 & 8,01 & 8,79 \\
\hline \multicolumn{2}{|c|}{ Prosek (B) } & 8,95 & 8,03 & 8,49 \\
\hline LSD & $\mathrm{A}$ & $\mathrm{B}$ & $A \times B$ & $B \times A$ \\
\hline 0,05 & 1,070 & 2,058 & 1,029 & 1,289 \\
\hline 0,01 & 1,774 & 2,994 & 1,497 & 2,043 \\
\hline
\end{tabular}

Masa krtola po biljci osnovna je komponenta prinosa. Prinos po jedinici površine direktno zavisi od broja biljaka, tj. broja kućica i mase krtola po biljci (kućici). Na masu krtola po biljci, direktno utiče gustina sklopa, tj. u gustom sklopu masa krtola po biljci opada, i obrnuto. Iz tog razloga veoma je bitno obezbediti optimalan vegetacioni prostor koji tada sa ostalim komponentama prinosa rezultira visokim prinosom po jedinici površine (llin, 1993).

Za masu krtole po biljci, pored visoko značajnog uticaja primenjenog tretmana, ustanovljeno je da je i sorta visoko značajno uticala na varijabilnost ove osobine (Tabela 3). Udeo sorte u ukupnoj varijabilnosti iznosio je $21,97 \%$, dok je udeo nastiranja iznosio $47,76 \%$. Da je sorta značajna za formiranje mase krtole po biljci ustanovili su i Tessema et al. (2020) i Bhatta et al (2020). Interakcija sorta $x$ nastiranje nije pokazala značajnost $u$ varijabilnosti ove osobine. Naime, udeo interakcije primenjene agrotehničke mere i gajene sorte u ukupnoj varija- 
bilnosti mase krtole po biljci učestvovao je sa manje od $1 \%(0,49 \%)$.

Tabela 3. Analiza varijanse za masu krtola po biljci Table 3. ANOVA for tuber weight per plant

\begin{tabular}{|l|c|c|c|}
\hline \multirow{2}{*}{ Izvor varijacije } & \multirow{2}{*}{ df } & \multicolumn{2}{|c|}{ Masa krtola po biljci $(\mathrm{g})$} \\
\cline { 3 - 4 } & & Sredinakvadrata & $\%$ \\
\hline Ponavljanja & 4 & 12060,736 & 26,77 \\
\hline Sorta $(\mathrm{A})$ & 1 & $39570,772^{\star *}$ & 21,97 \\
\hline Pogreška po a & 4 & 428,723 & 0,95 \\
\hline Tretman $(\mathrm{B})$ & 1 & $86075,510^{\star *}$ & 47,76 \\
\hline A $\times$ B & 1 & 889,289 & 0,49 \\
\hline Pogreška po b & 8 & 464,782 & 2,06 \\
\hline
\end{tabular}

${ }^{*} p \leq 0,05 ;{ }^{* *} p \leq 0,01$

Prosečna masa krtola po biljci kod sorte Riviera bila je statistički značajno veća od prosečne mase krtola po biljci kod druge proučavane sorte (Tabela 4). Visoka značajnost ustanovljena i između prosečnih ostvarenih vrednosti mase krtola u kontrolnoj varijanti i usled primene malč folije. Trogodišnji prosek proučavane osobine u klasičnom sistemu proizvodnje (bez nastiranja) bio je statistički značajno manji u odnosu na varijantu sa tretmanima, a razlika između sorti po tretmanima takođe je pokazala statističku značajnost. Statistički značajno više ostvarene vrednosti mase krtola po biljci ostvarene u uslovima proizvodnje sa nastiranjem dobili su i Bhatta et al (2020), Bharati et al (2020), Majumder et al (2016).

Tabela 4. Prosečne srednje vrednosti i vrednosti LSD testa za masu krtola po biljci $(g)$

Table 4. The overall mean values and $L S D$ values for tuber weight per plant (g)

\begin{tabular}{|c|c|c|c|c|}
\hline \multirow{2}{*}{\multicolumn{2}{|c|}{ Sorta (A) }} & \multicolumn{2}{|c|}{ Tretman (B) } & \multirow{2}{*}{$\begin{array}{c}\text { Prosek } \\
\text { (A) }\end{array}$} \\
\hline & & $\mathrm{K}$ & $\mathrm{N}$ & \\
\hline \multicolumn{2}{|c|}{ Cleopatra } & 603,21 & 721,08 & 662,15 \\
\hline \multicolumn{2}{|l|}{ Riviera } & 678,84 & 823,38 & 751,11 \\
\hline \multicolumn{2}{|c|}{ Prosek (B) } & 641,02 & 772,23 & 706,63 \\
\hline LSD & A & B & $A \times B$ & $B \times A$ \\
\hline 0,05 & 25,705 & 62,885 & 31,442 & 33,841 \\
\hline 0,01 & 42,632 & 91,491 & 45,745 & 52,861 \\
\hline
\end{tabular}

Prinos mladog krompira zavisi od velikog broja faktora. Pored standardnih agrotehničkih mera (navodnjavanje, đubrenje, zaštita) poseban značaj ima i nastiranje, što potvrđuju i rezultati ovog istraživanja (Tabela 5). lako su brojni autori ustanovili značajan uticaj sorte na ukupnu varijabilnost prinosa krtole (Jama Rodzenska et al., 2021; Poštić i dr., 2017; Parvizi et al, 2017; Bošković-Rakočević, Pavlović, 2009; Marković i dr., 2006; Hamouz et al, 2006) analizom dobijenih rezultata ustanovljeno je da na ukupnu varijabilnost prinosa krtola mladog krompira, u trogodišnjem proseku sorta uticala $8 \%$. Da sorta ne utiče na prinos krtole ustanovili su i Keleta et al.
(2018). Najveći uticaj u ukupnoj varijabilnosti prinosa imala je primenjena agrotehnička mera - nastiranje $(44,14 \%)$.

Trogodišnji prosečen prinos ostvaren pri upotrebi nastiranja bio je statistički značajno veći u odnosu na kontrolnu varijantu (Tabela 6 ). Poređenjem tretmana po sortama (interakcija $A \times B$ ) ustanovljena je visoko značajna razlika kod obe proučavane sorte za osobinu prinos krtole, dok poređenjem sorti po tretmanima (interakcija $B \times A$ ) nije ustanovljena statistička značajnost. Rezultati dobijeni u ovom istraživanju u saglasnosti su sa rezultatima Bhatta et al. (2020). Pomenuti autori su proučavali uticaj različitih vrsta malč folije na prinos krtola krompira i morfološke osobine i ustanovili značajan uticaj nastiranja na prinos krompira. Najveći prinos tržišnih krtola ustanovljen je kada je korištena perforirana crna malč folija. Autori ovo objašnjavaju činjenicom da neperforirana folija smanjuje efekat padavina što negativno utiče na prinos. Pozitivan uticaj na ukupan prinos krtola ustanovili su i Yagi et al. (2020), koji su proučavali uticaj živinskog đubriva i svežeg malča na organsku proizvodnju krompira, kao i Bharati et al (2020), koji su istraživali različite tipove malč materijala na prinos i komponente prinosa krompira. Pozitivan uticaj nastiranja na prinos krtola utvrdili su i Oljača (2016) i Oljača et al. (2018). Pomenuti autori su takođe ispitivali uticaj različitih vrsta malč materijala u kombinaciji sa navodnjavanjem na morfološke osobine i prinos krtole krompira. Najveći prinos dobili su pri korišćenju prirodnog materijala za nastiranje (slame) uz navodnjavanje, što objašnjavaju činjenicom da je u periodu formiranja i nalivanja krtola najpovoljniji temperaturni režim bio pri upotrebi organskog malč materijala, što se uz dovoljne količine vode pozitivno odrazilo na prinos krtola.

Tabela 5. Analiza varijanse za prinos krtole Table 5. ANOVA for tuber yield

\begin{tabular}{|l|c|c|c|}
\hline \multirow{2}{*}{ Izvor varijacije } & \multirow{2}{*}{$\mathrm{df}$} & \multicolumn{2}{|c|}{ Prinos (t/ha) } \\
\cline { 3 - 4 } & & Sredinakvadrata & $\%$ \\
\hline Ponavljanja & 4 & 15,789 & 24,78 \\
\hline Sorta $(\mathrm{A})$ & 1 & 20,426 & 8,02 \\
\hline Pogreška po a & 4 & 11,968 & 18,79 \\
\hline Tretman $(\mathrm{B})$ & 1 & $112,458^{\text {** }}$ & 44,14 \\
\hline $\mathrm{A} \times \mathrm{B}$ & 1 & 0,165 & 0,07 \\
\hline Pogreška po b & 8 & 1,337 & 4,20 \\
\hline
\end{tabular}

${ }^{*} p \leq 0,05 ;{ }^{* *} p \leq 0,01$

Azad et al. (2015) su ispitivali uticaj sorte i četiri različite vrste malča (providan, beli, crni i dupli malč) na morfološke osobine krompira i prinos krtola krompira. U svom istraživanju pomenuti autori su ustanovili da je primenjena sorta imala visoko značajan uticaj na varijabilnost prinosa, dok primenjen tretman nije značajno uticao na prinos krtola, sa čime 
se rezultati našeg istraživanja ne slažu. Harahagazwe et al. (2010) takođe nisu ustanovili značajnost upotrebe nastiranja na prinos krompira.

Tabela 6. Prosečne srednje vrednosti i vrednosti LSD testa za prinos krtole (t/ha)

Table 6. The overall mean values and $L S D$ values for tuber yield ( $t / h a)$

\begin{tabular}{|l|c|c|c|c|}
\hline \multirow{2}{*}{ Sorta (A) } & \multicolumn{2}{|c|}{ Tretman (B) } & Prosek \\
\cline { 3 - 4 } & $\mathrm{K}$ & $\mathrm{N}$ & $(\mathrm{A})$ \\
\hline \multicolumn{2}{|l|}{ Cleopatra } & 30,074 & 34,998 & 32,536 \\
\hline Riviera & 32,277 & 36,838 & 34,557 \\
\hline \multicolumn{2}{|l|}{ Prosek (B) } & 31,176 & 35,918 & 33,547 \\
\hline LSD & $\mathrm{A}$ & $\mathrm{B}$ & $\mathrm{A} \times \mathrm{B}$ & $\mathrm{B} \times \mathrm{A}$ \\
\hline 0,05 & 4,295 & 3,373 & 1,687 & 4,451 \\
\hline 0,01 & 7,123 & 4,908 & 2,454 & 7,306 \\
\hline
\end{tabular}

\section{ZAKLJUČAK / CONCLUSION}

$\mathrm{Na}$ osnovu trogodišnjih rezultata dobijenih $\mathrm{u}$ ovom eksperimentu mogu se izvesti sledeći zaključci:

- primenjena agrotehnička mera (nastiranje) imala je visoko značajan pozitivan uticaj na sve tri proučavane osobine: broj krtola po biljci, masa krtola po biljci i prinos krtola po jedinici površine;

- primenjena sorta značajnost je pokazala za sve tri proučavane osobine

Interakcija tretmana i sorte je imala značajan uticaj samo na varijabilnost osobine broj krtola po biljci

Na osnovu dobijenih rezultata može se zaključiti da malčovanje ima pozitivan uticaj na postizanje višeg i stabilnijeg prinosa, što pruža veću mogućnost za širu primenu ove specifične agrotehničke mere u proizvodnji mladog krompira.

\section{LITERATURA / REFERENCES}

[1] Amidžić, B., Biočanin, R. (2005). Pesticidi u životnoj sredini i uticajni faktori na zdravlje, Ecologica, 12(46), 49-58.

[2] Azad, B., Hassandokht, M. R., Parvizi, K. (2015). Effect of mulch on some characteristics of potato in Asadabad, Hamedan, IJAAR, 6 (3), 139-147.

[3] Bharati, S., Joshi, B., Dhakal, R., Paneru, S., Dhakal, S. H., Joshi, K. R. (2020). Effect of different mulching on yield and yield attributes of potato in Dadeldhura district, Nepal, Malaysian Journal of Sustainable Agriculture, 4(2), 54-58.

[4] Bhatta, M., Shrestha, B., Devkota, A. R., Joshi, K. R., Bhattarai, S., Dhakal, U. (2020). Effect of plastic mulches on growth and yield of potato (Solanum tuberosum L.) in Dadeldhura, Nepal,
Journal of Agriculture and Natural Resources, 3(2), 228-240.

[5] Bošković-Rakočević, L., Pavlović, R. (2009). Uticaj azota na prinos i sadržaj nitrata kod mladog krompira u plasteničkoj proizvodnji, Acta agriculturae Serbica, 14 (27), 93-99.

[6] Broćić, Z., Barčik, B. (2003). Priprema za sadnju krompira-naklijavanje i sečenje krtola, Savremeni povrtar, 5, 32-33.

[7] Dinić, J., Bukovala, J., Ivannikov, N. (2021). Ekološka politika Evropske unije. Ecologica, 28 (101), 16-21.

[8] GenStat Release 9.1 (PC/Windows XP), Copyright 2006, Lawes Agricultural Trust (Rothamsted Experimental Station).

[9] Hamouz, K., Lachman, J., Dvořák, P., Trnková, E. (2006). Influence of non-woven fleece on the yield formation of early potatoes, Plant soil environ., 52 (7), 289-294.

[10] Harahagazwe, D., Ledent, J. F., Rusuku, G. (2010). Effects of rice straw mulch and planting density on potato growth and performance in lowlands of Burundi, Experimental Agriculture, 46 (4), 501-518.

[11] FAO (2019). https://www.fao.org

[12] Ilin, Ž. (1993). Uticaj đubrenja i navodnjavanja na prinos i kvalitet krompira. Doktorska disretacija, Univerzitet u Novom Sadu, Poljoprivredni fakultet, 1-108 str.

[13] Ilin, Ž., Bugarčić, Ž., Adamović, B., llin, S. (2015). Tehnologija proizvodnje i sortiment krompira, Biljni lekar, 43 (6), str. 501-511.

[14] Iqbal, R., Raza, M. A. S., Valipour, M., Saleem, M. F., Zaheer, M., Ahmad, S., Toleikiene, M., Haider, I., Aslam, M. U., Nazar, M. A. (2020). Potential agricultural and environmental benefits of mulches - a review, Bulletin of the National Research Centre, 44, 75-90.

[15] Jama Rodzenska, A., Janik, G., Walczak, A., Adamczewska Sowinska, K., Sowinski, J. (2021). Tuber yield and water eficiency of early potato varieties (Solanum tuberosum L.) cultivated under various irrigation levels, Scientific Reports, 11, 19121.

[16] Keleta, B. T., Lal, S., Naqvi, S. D. Y. (2018). Effect of planting dates and varieties on growth and yield of potato (Solanum tuberosum L.) in Hamelmalo area, Journal of Eco-friendly Agriculture, 13 (1), 46-52.

[17] Majumder, D. A. N., Nath, S.C., Kabir, M. A., Majumder, S. (2016). Effect of mulching materials on mini-tuber production of potato from in vitro plantlets, Nusantara Bioscience, 8 (1), 123-127. 
[18] Marković, V., Bajkin, A., Vračar, Lj., Ponjičan, O., Mišković, A., Vujasinović, V. (2006). Uslovi za proizvodnju kvalitetne sirovine za zamrzavanje mladog krompira, Časopis za procesnu tehniku $i$ energetiku u poljoprivredi/PTEP 10(1-2), 16-19 .

[19] Oljača, J. (2016). Uticaj sorte i tehnologije gajenja krompira na otpornost prema stresu, Doktorska disertacija, Poljoprivredni fakultet, Beograd, 144 str.

[20] Oljača, J., Broćić, Z., Momirović, N., Poštić, D., Pantelić, D., Rudić, J., Momčilović, I. (2018). Effects of cultivar and mulching on the potato yield, AGROFOR International Journal, 3(1), 132-138.

[21] Parvizi, K., Hassandokth, M., Azad, B. (2017). Effect of different plastic mulch on growth and yied of potato (Solanum tuberosum), Journal of Horticultural Science, 31(3), 543-554.

[22] Poštić, D., Momirović, N., Broćić, Z., Đukanović, L., Štrbanović, R., Terzić, D., Stanisavljević, R. (2017). The effect of genotype and ecological conditions on the yield components of potatoes.
Journal on Processing and Energy in Agriculture, 21(4), 207-210.

[23] Radić, D., Racić, G., Bojović, M., Prorok, V., Jovanović, Lj., Kredics, L., Panković, D. (2020). Uticaj bakterije na morfo-fiziološke karakteristike paradajza (Solanum licopersicum L.), Ecologica, 27(100), 617-623.

[24] Stefanović, R., Carić, M., Stojanović, V. (2009). Razvoj poljoprivrede u globalnim uslovima i implikacije na životnu sredinu. Ecologica, 16(55), $501-$ 505.

[25] Stefanović, R., Obradović, S. (2010). Uticaji i efekti globalnih klimatskih promena na poljoprivrednu i svetsku prehrambenu sigurnost, Ecologica, 17 (59), 325-331.

[26] Tessema, L., Mohammed, W., Abebe, T. (2020). Evaluation of potato (Solanum tuberosum L.) varieties for yield and some agronomic traits, Open Agriculture, 5, 63-74.

[27] Yagi, R., Xavier de Nazareno, N. R., Kawakami, J. (2020). Poultry litter ans fresh mulch of Elephant grass improve the organic potato production, Pesquisa Agropecuaria Tropical, 50, e57585. 